\title{
Early discharge summaries
}

\author{
Shona A. Walker, Gisela A. E. Boehlhoff and John M. Eagles
}

\begin{abstract}
An earlier survey of general practitioners in Grampian established their priorities for information they wished to leam from earty discharge summaries on psychiatric patients. This survey resulted in changes to the format of the earty discharge summary. An audit of information provided before and offer these changes found significant improvement in 7 out of 10 Hems regarded by general practitioners as being of greatest importance.
\end{abstract}

When psychiatric patients are discharged from hospital, communication with primary care teams through early discharge summaries is often poor, giving rise to disquiet on the part of general practitioners (GPs) (Orrel \& Greenberg. 1986: Craddock, 1990). In geriatric medicine, where the issue has been closely studied, poor communication at the time of patients' discharge is associated with higher readmission rates (Williams \& Fitton, 1990) and the prescription of inappropriate medication in the community (Cochrane et al, 1992).

In an earlier paper (Walker \& Eagles, 1994), we reported the views of Grampian GPs on communication when psychiatric patients are discharged from hospital. As a result of that survey a new format of early discharge summary was introduced. GPs identified 10 items which they wished to be covered in the early discharge letter and these are listed in Table 1 . We report on an audit of the information in early discharge summaries before and after the introduction of the new format.
Table 1. Top ten items identified by GPs for inclusion in an early discharge summary

\begin{tabular}{ll}
\hline Items of greatest importance & \\
\hline Diagnosis & $85 \%$ \\
Discharge treatment & $84 \%$ \\
Mental state examination at discharge & $72 \%$ \\
Date of discharge & $71 \%$ \\
Advice regarding management & $70 \%$ \\
In-patient treatment & $67 \%$ \\
Prognosis & $65 \%$ \\
Information given to the patient & $62 \%$ \\
Date of admission & $52 \%$ \\
Reason for admission & $47 \%$ \\
\hline
\end{tabular}

\section{The study}

The new format for the early discharge summary was introduced to the in-patient population at the Royal Cornhill Hospital in October 1993. A copy of the early discharge summary was filed in the psychiatric case notes. A further formal discharge letter would be completed after discharge, a copy of which would also be included in the case notes. From the Medical Records Department at Royal Cornhill Hospital, 50 patients undergoing discharge with old format letters and 50 patients discharged with new format letters were selected at random. These 100 letters were rated for presence or absence of the 10 items deemed by the GPs to be of most importance.

Table 2. Information present in old and new letter format

\begin{tabular}{|c|c|c|c|}
\hline Information liems' & Old format $(n=50)$ & Now format $(n=50)$ & \\
\hline $\begin{array}{l}\text { Diagnosis } \\
\text { Discharge treatment } \\
\text { Mental state at discharge } \\
\text { Date of discharge } \\
\text { Advice on management } \\
\text { In-patient treatment } \\
\text { Prognosis } \\
\text { Information given to patient } \\
\text { Date of admission } \\
\text { Reason for admission }\end{array}$ & $\begin{array}{r}38 \\
50 \\
4 \\
50 \\
15 \\
18 \\
1 \\
0 \\
35 \\
35\end{array}$ & $\begin{array}{l}45 \\
48 \\
41 \\
49 \\
45 \\
48 \\
16 \\
16 \\
50 \\
49\end{array}$ & $\begin{array}{l}\chi^{2}=2.65^{*}, P=0.11 \\
\chi^{2}=0.51^{*}, P=0.47 \\
\chi^{2}=32.36^{*}, P<0.001 \\
\chi^{2}=0.0^{*}, P=1.0 \\
\chi^{2}=35.04^{*}, P<0.001 \\
\chi^{2}=37.48^{*}, P<0.001 \\
\chi^{2}=13.89^{*}, P<0.001 \\
\chi^{2}=16.74^{*}, P<0.001 \\
\chi^{2}=15.37^{*}, P<0.001 \\
\chi^{2}=12.57^{*}, P<0.001\end{array}$ \\
\hline
\end{tabular}

*All $\chi^{2}$ with 1 d.f.

1. Listed in descending importance as rated by GPs. 


\section{Findings}

Table 2 shows that for seven items there was a significant improvement in the information provided. With the new format, $90 \%$ of letters contained $70 \%$ or more of the relevant information. The comparable figure with the old format was only $8 \%$.

\section{Comment}

Canvassing the views of general practitioners and changing the format of our early discharge letter does appear to have resulted in GPs receiving more of the information which they consider to be of relevance. (A copy of our revised letter is available from the authors upon request in case services wish to adopt it in whole or in part.)

\section{References}

Cochrane, R. A., MANDAl, A. R., Ledger-Scott, M., et al (1992) Changes in drug treatment after discharge from hospital in geriatric patients. British Medical Joumal, 305. 694-696.

CRADDOCK, N. (1990) Audit of psychiatric discharge summaries. Psychiatric Bulletin, 14, 618-620.

ORREL, M. \& GREENBERG. M. (1986) What makes psychiatric discharge summaries useful to general practitioners? Psychiatric Bulletin, 10. 107-109.

WALKER, S. A. \& EAGLES. J. M. (1994) Review of the early discharge summary of the Gramplan Area. Psychiatric Bulletin, 18, 140-141.

Williams, E. L. \& FTton, F. (1990) General practitioner response to elderly patients discharged from hospital. British Medical Journal, 300. 159-161.

*Shona A. Walker, Senior Registrar, Gisela A. E. Boehlhoff, Senior House Officer and John M. Eagles, Consultant Psychiatrist, Rehabilitation Department, Royal Cornhill Hospital, Cornhill Road, Aberdeen AB9 2ZH

*Correspondence 